\title{
Nurses Perception of their Workload and Pay in the Era of HIV/AIDS in Gaborone and the Surrounding Areas of Botswana
}

\author{
Keratilwe Bodilenyane \\ Ministry of Agriculture, Department of Animal Production \\ P. O. Box 342, Mochudi, Botswana \\ Email: kbodilenyane@gov.bw \\ Baakile Motshegwa (Corresponding Author) \\ University of Botswana, Department of political and Administrative Studies \\ Private Bag UB00705, Gaborone, Botswana \\ Email: Motshegwa@mopipi.ub.bw
}

Accepted: February 23, 2012 Published: March 24, 2012

Doi:10.5296/ijhrs.v2i1.1440ＵRL: http://dx.doi.org/10.5296/ijhrs.v2i1.1440

\begin{abstract}
The purpose of this research paper was to explore how HIV/AIDS manipulate nurses' perception of their workload and pay in the era of HIV/AIDS in Gaborone and the surrounding areas of Botswana. The health care sector in Botswana is overwhelmed by HIV/AIDS, and this takes a toll on the nurses because they are the ones at the forefront in the fight against this demanding and risky illness at the workplace. The focus in this study was on the workload and pay in the era of HIV/AIDS. The general picture that emerges from the current study is that nurses are dissatisfied with their pay and to some extent the workload and this supports some of the earlier studies which reinforce their importance in the workplace. The study used both primary and secondary sources of information. For the purpose of this study convenience sampling was used. A questionnaire was used for data collection. The study adapted Index of Organizational Reactions (IOR). The findings of the current study will help the government to design strategies that will increase the level of job satisfaction among the nurses in the public health care sector of Botswana.
\end{abstract}

KEYWORDS: job satisfaction, work load, pay, nursing, HIV/AIDS

\section{Introduction}

It is particularly a difficult time for both the health care providers and the government, to keep pace with the high demands brought by HIV/AIDS in the health care sector. In the UN Assembly in June 2002, the then President of Botswana, Mr. Festus Mogae said the 
HIV/AIDS crisis in Botswana is of the highest magnitude (Ganetsang, 2010). Hence the advent of HIV/AIDS has had a devastating impact on the health care sector and as such has changed the nature of the nursing profession (Tshweneyagae, 2007). Therefore if the working life of the nurses is to be improved, it is necessary to pay attention to their needs, motives, desires and the kind or work environment that will enhance their job satisfaction. The current study is important as it adds to the body of knowledge of management especially by drawing from the African perspective.

Although job satisfaction has been studied extensively, most of research did not single out example of sources of job satisfaction or dissatisfaction at the work place and discuss them in line with the factors of job satisfaction and their impacts. For example when one discusses the nature of the nursing profession, it is a profession where the employees (the nurses) deals with highly infectious diseases like HIV/AIDS and communicable disease like Tuberculosis. Hence this study has singled out HIV/AIDS as one illness that can have an effect in the nursing profession when compared with dimensions of job satisfaction.

The main aim of this paper was to explore nurses' opinion on job satisfaction in the era of HIV/AIDS in the Public Health Sector. There is lack of consensus over the meaning of job satisfaction in nursing (Tovey \& Adams, 1999). Therefore, in this study, job satisfaction will be operationalized as the extent to which people gauge their job in terms of what they expect from the job, looking at the work environment and the demands of their job. As for nursing it is a healthcare profession focused on the care of individuals, families, and communities so that they may attain, maintain, or recover optimal health and quality of life from birth to death (WHO, 2006). Another equally important term is HIV/AIDS which is a deadly disease that damages the body's immune system cells and the body becomes vulnerable to illness and infection. And as such there is no cure for HIV/AIDS. HIV is transmitted from person to person through the exchange of infected body fluids such as blood, semen, breast milk and vaginal secretions (WHO, 2006).

\section{The Study}

According to Herzberg (1966) there are two types of work motivation that are intrinsic and extrinsic. Hence this study will discuss two of the extrinsic factors by Herzberg that is workload and pay. These factors rather than describe man's relationship to what he does, they describe his relationship to the context or environment in which he does the job (Herzberg, 1966). Hence if these factors are not adequately present they could lead to job dissatisfaction. The presence of both the motivators and hygiene factors in the workplace will mean there is some perceived fairness.

\subsection{Workload}

Gardulf et al. (2008) asserted that studies have revealed that nurses' perception of their work situation is influenced by their workload. The effects of HIV/AIDS include: increased burden of disease such as TB, malnutrition, diarrhoea, meningitis, pneumocystis carinii pneumonia (PCP) in the form of opportunistic infections associated with HIV infection, increased service 
needs associated with caring for the illness and for which is the limited resource capacity (Tawfik, 2006). This has been supported by Dr Khan, the founding Head of National AIDS Coordinating Agency (NACA) that the epidemic has put additional demands on the health care sector in Botswana (IRIN, 2011). For example in 2008, the health sector was so overwhelmed, because malaria and TB which are HIV/AIDS related illness were very prevalent and stretched the health care system to the limit. Also the Hospital Superintendent of Princess Marina of 2004, Dr Moffat argued that the high prevalence of HIV/AIDS rate-currently at $37.3 \%$ has led to overcrowding in hospitals (IRIN, 2011). The superintendent argued that $70 \%$ of their patients are suffering from HIV/AIDS related diseases. Generally this implies that people living with HIV/AIDS have range of health care needs, which have increased the workload in hospitals.

However, the improvements by government of Botswana to employ lay counsellors (who are form five leavers with a pass in English) should be appreciated because it promises improvements in reduction of workload. Nevertheless, one needs to understand that the lay consellors do not have the expertise that the nurses have and as such the bulk of the technical work is done by the nurses. Also, lay counselors may not be effective in reducing the workload due to the bottlenecks to treatment provision which are bureaucratic and cumbersome procedures for administration of drugs to patients (Economic Commission for Africa, 2004). In contrast, Blau and Lunz (1998) in their study found that increased tasks responsibility is related to overall job satisfaction. This concurs with Herzberg's two factor theory which postulates that employees get fulfillment from being tasked with more responsibility, as this shows accountability on the side of the employee.

It is therefore hypothesized that increased workload due to the existence of HIV/AIDS will lead to the nurses' dissatisfaction with their work.

\subsection{Pay}

Pay is one factor that contributes to employee personal goals indirectly. This is what Herzberg refers to as an extrinsic factor, because it leads to fulfillment indirectly. The term pay in a wider sense encompasses direct monetary payments and a range of financial welfare benefits (including pension, company cars, cheap loans, etc.) (Salamon, 2000). The importance of pay as a determinant of job satisfaction is highly pronounced in most of the research carried out. Studies have revealed that nurses felt that they did not get paid enough for what they deserved. Hu and Liu (2004:12) note that, most nurses in China felt they are underpaid and their salary does not reflect what they contribute, and comparing their profession with other profession it seems theirs is underpaid. Nurses in Botswana have also perceived their pay to be low despite the fact that nursing is an essential service (Tshweneyagae, $2007 \&$ Fako, 2000). Therefore, the nurses who are satisfied with their salary are satisfied with their job.

Furthermore, pay could be one way of recognizing the significance of nurses in the health care sector. This is supported by Herzberg (1966) who argued that pay takes significance as a source of satisfaction when it is perceived as a form of recognition. The nurses in Botswana 
have complained about the failure of government to recognize the important role they play in the society. Attesting to this are the nurses who migrated to work outside the country and thereafter upon their return to Botswana were made to wait for a long period of time before they can be absorbed in the system or re-employed (Tshweneyagae, 2007). It is argued that these nurses were re-employed at an entry scale without recognizing the experience accrued from where they had been working, (Botswana parliamentary debates 2006 in Tshweneyagae, 2007).

In an alternative view, Savery (2007) found salary to be ranked very low as a satisfier for nurses who ranked it tenth in the list of twelve items. Savery (2007) asserted that it is important for hospital administrators who have generally concentrated on giving more money as a motivator rather than consider other aspects of the reward package which appear to offer more possibility of improving job satisfaction. He concurs with Herzberg that salary should not be perceived as the greatest motivator but rather be considered as hygiene factor. Also in their study $\mathrm{Hu}$ and Liu (2004) reports that pay was rated as the least satisfying aspect of work followed by promotions. This confirms that hygiene factors alone without motivators make satisfaction incomplete. It is therefore, hypothesized that low pay will have a negative effect on nurses perception of their job in the era of HIV/AIDS.

\section{Research Design and Methodology}

\subsection{Sample}

The hospitals were purposively selected in Gaborone and the surrounding towns. The questionnaire was distributed to the respondents and had the following components for data collection;

(a). Biographical data such as participant's age, gender, experience and occupational level.

(b). Adapted Index of Organizational (IOR) developed by Dunham and Smith in 1979 from Fields (2002).

\subsection{Procedure}

Convenience sampling was used in this study. Therefore nurses who reported for duty on two selected days made up the sample of the study. The participants were visited from the wards in which they were based on those two particular days. Nurses who did not report for duty on the two selected days were excluded from the sample. The targeted sample size was 70 . However 100 questionnaires were distributed to the respondents to increase the response rate. A cover letter was written and affixed to the questionnaire to explain the purpose and nature of the study. Of 100 questionnaires that were distributed to the respondents, 90 completed questionnaires were returned.

\subsection{Validity and Reliability}

Five nurses from Extension 2 Clinic in Gaborone were used for pre-testing the survey before sending it to the real respondents. The nurses for pre-testing of the survey did not participate in the actual survey. IOR has been commonly used scale to assess job satisfaction and thus has been tested as reliable by many researchers (Fields, 2002). It has demonstrated reliability, with coefficient alpha values ranging from .82 to .83 (Lee \& Johnson in Fields, 2002). 


\subsection{Methods of Data Analysis}

Statistical Package for Social Sciences (SPSS) was used for data analysis. The data was cleaned. Data cleaning refers to deleting cases with missing values (Motshegwa, 2008).

4. Analysis and Discussions of Results

\subsection{Nurses Opinion on Organizational Variables}

Cross tabulation was used to capture nurse's opinion on the two organizational variables.

Table 1: $\quad$ Nurses Opinion on the Workload in the advent of HIV/AIDS

\begin{tabular}{|c|c|c|c|c|c|c|c|}
\hline & & \multicolumn{2}{|c|}{ Male } & \multicolumn{2}{|c|}{ Female } & \multicolumn{2}{|c|}{ Total } \\
\hline & & Frequency & percent & Frequency & Percent & Frequency & Percen \\
\hline \multirow{3}{*}{$\begin{array}{c}\text { I feel the advent of } \\
\text { HIV/AIDS has made my } \\
\text { workload }\end{array}$} & Heavy & 10 & 45.5 & 24 & 50.0 & 34 & 48.6 \\
\hline & Neutral & 6 & 27.3 & 17 & 35.4 & 23 & 32.9 \\
\hline & not heavy & 6 & 27.3 & 7 & 14.6 & 13 & 18.6 \\
\hline \multirow{3}{*}{$\begin{array}{l}\text { how does the amount of } \\
\text { work you are expected to } \\
\text { do with regards to } \\
\text { HIV/AIDS patients } \\
\text { influence the way you do } \\
\text { your job }\end{array}$} & does not allow good job & 3 & 13.6 & 15 & 31.3 & 18 & 25.7 \\
\hline & Neutral & 12 & 54.5 & 15 & 31.3 & 27 & 38.6 \\
\hline & allows good job & 7 & 31.8 & 18 & 37.5 & 25 & 35.7 \\
\hline \multirow{3}{*}{$\begin{array}{l}\text { How does the amount of } \\
\text { work you are expected to } \\
\text { do on HIV/AIDS Patients } \\
\text { influence the way you do } \\
\text { your job }\end{array}$} & Unfavorable & 8 & 36.4 & 19 & 40.4 & 27 & 39.1 \\
\hline & Neutral & 10 & 45.5 & 13 & 27.7 & 23 & 33.3 \\
\hline & Favourable & 4 & 18.2 & 15 & 31.9 & 19 & 27.5 \\
\hline \multirow{3}{*}{$\begin{array}{l}\text { How do you feel about the } \\
\text { amount of work you are } \\
\text { expected to with regards } \\
\text { to HIV/AIDS }\end{array}$} & Dissatisfied & 8 & 36.4 & 16 & 34.0 & 24 & 34.8 \\
\hline & Neutral & 5 & 22.7 & 11 & 23.4 & 16 & 23.2 \\
\hline & Satisfied & 9 & 40.9 & 20 & 42.6 & 29 & 42.0 \\
\hline
\end{tabular}

The results on nurse's opinion about their workload are ambiguous and this information is contained in Table 1. Despite the presence of lay counsellors whom we expect to reduce the HIV/AIDS workload, the results of the current study indicate that there are some nurses who are not satisfied with the workload in the advent of HIV/AIDS. It was found that most nurses reported that the advent of HIV/AIDS has made their workload heavy. This could be attributed to the reason that the effects of HIV/AIDS include increased burden of disease and increased service needs associated with caring for the sick and for which there are limited resources. This has also been supported by Dr Khan, former Head of NACA that the epidemic has put additional demands on the health care (IRIN, 2011). Another factor for the dissatisfaction with the increased workload in the advent of HIV/AIDS could be due to the fact that lay counsellors cannot do the technical part of the job hence this leave the nurses with a lot of work to do. The findings are consistent with those by Pillay (2009) who found that excessive workload has shown to significantly contribute to dissatisfaction. The findings 
also confirm the results by several studies that reasons for increased workload could be from additional responsibilities, decrease in staff numbers due to resignation, new environment/job and merger (Mafuya \& Peltzer, 2005, Gardulf et al., 2008 and Tawfik, 2006). In addition nurses' dissatisfaction due to workload may be exacerbated by high-patient-to nurse ratio, which if not properly addressed, can become cyclical (Aiken et al., 2003).

However, they were some nurses who indicated that they were satisfied with the workload in the advent of HIV/AIDS. The current findings are, therefore, consistent with the earlier findings by Fako (2000) who found workload to be among the least important factors affecting job satisfaction. According to Fako (2000) this could be due to high commitment, high level of supervisor recognition and support that the nurses enjoyed. In addition the findings could be attributed to the fact that some of the nurses appreciate the help they get from the lay counsellors. Therefore, the current findings do not support hypothesis 1 , that workload in the era of HIV/AIDS will lead to dissatisfaction. This is because nurses have mixed feelings about their workload as alluded above.

Table 2: $\quad$ Nurses Opinion of their Pay in the advent of HIV/AIDS

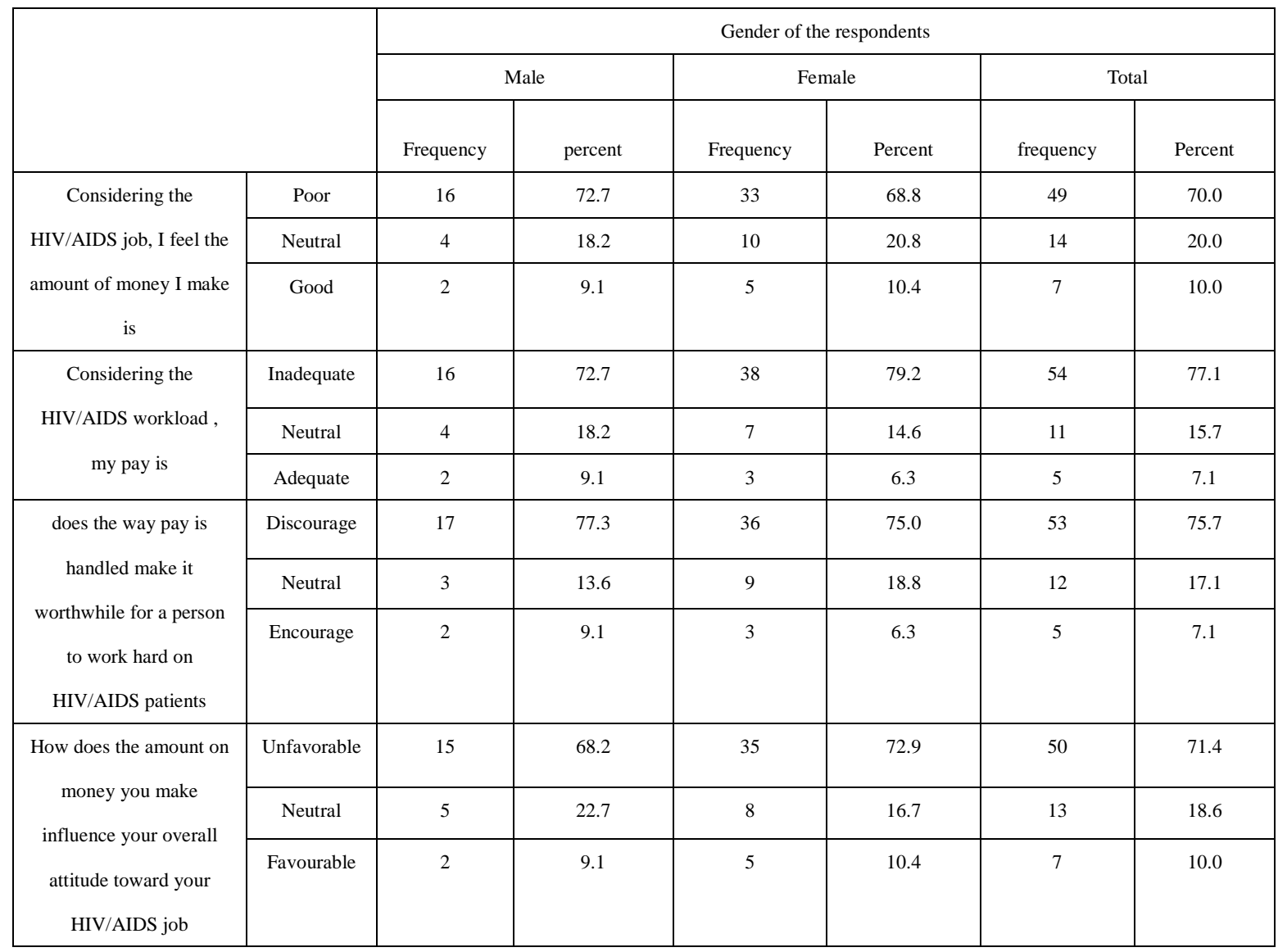

Majority of nurses are not satisfied with their pay and this information is illustrated in Table 2. The current findings support hypothesis 2, that low pay will have a negative effect on the nurses perception of their job in the era of HIV/AIDS. The nurses in Botswana are absolutely 
dissatisfied with the pay they get in relation to addressing HIV/AIDS pandemic. Considering the HIV/AIDS job, the nurses feel the amount of money they make is poor, inadequate and reported that the way pay is handled discourages hard work. This means that the nurses feel the cost of nursing profession outweigh what they expect they should benefit from the profession. The findings are consistent with the earlier findings by Curtis (2007), Fako (2000), $\mathrm{Hu}$ and Liu (2004) and Pillay (2009) who found majority of respondents not happy with pay and felt they did not get enough for what they did.

Given that Botswana has the highest HIV/AIDS incidence rate compared to other countries in the world (USAID, 2010) nurses would expect the government to consider this when designing their pay system. This is consistent with the expectancy theory, that postulates that the satisfaction gained by an individual is governed by the difference between the amount of some valued outcome that a person receives and the amount of that outcome he feels he should receive (Vroom, 1964). In addition the current findings corroborate with the theory by Spector (1997) that what makes a job satisfying or unsatisfying does not depend only on the nature of the job, but also on the expectations that individuals have of what their job should provide. This is also substantiated by the social exchange theory espoused by Kelly and Thibaut, in Coshow (2009) which predicts that when the benefits of maintaining an existing employment relation are outweighed by its costs, employees will tend to seek out a more rewarding situation, in this case a new job. Hence need for government to come up with pay systems that will appreciate the role of the nurses in the health care sector.

Table 3: $\quad$ The relationship between workload and pay

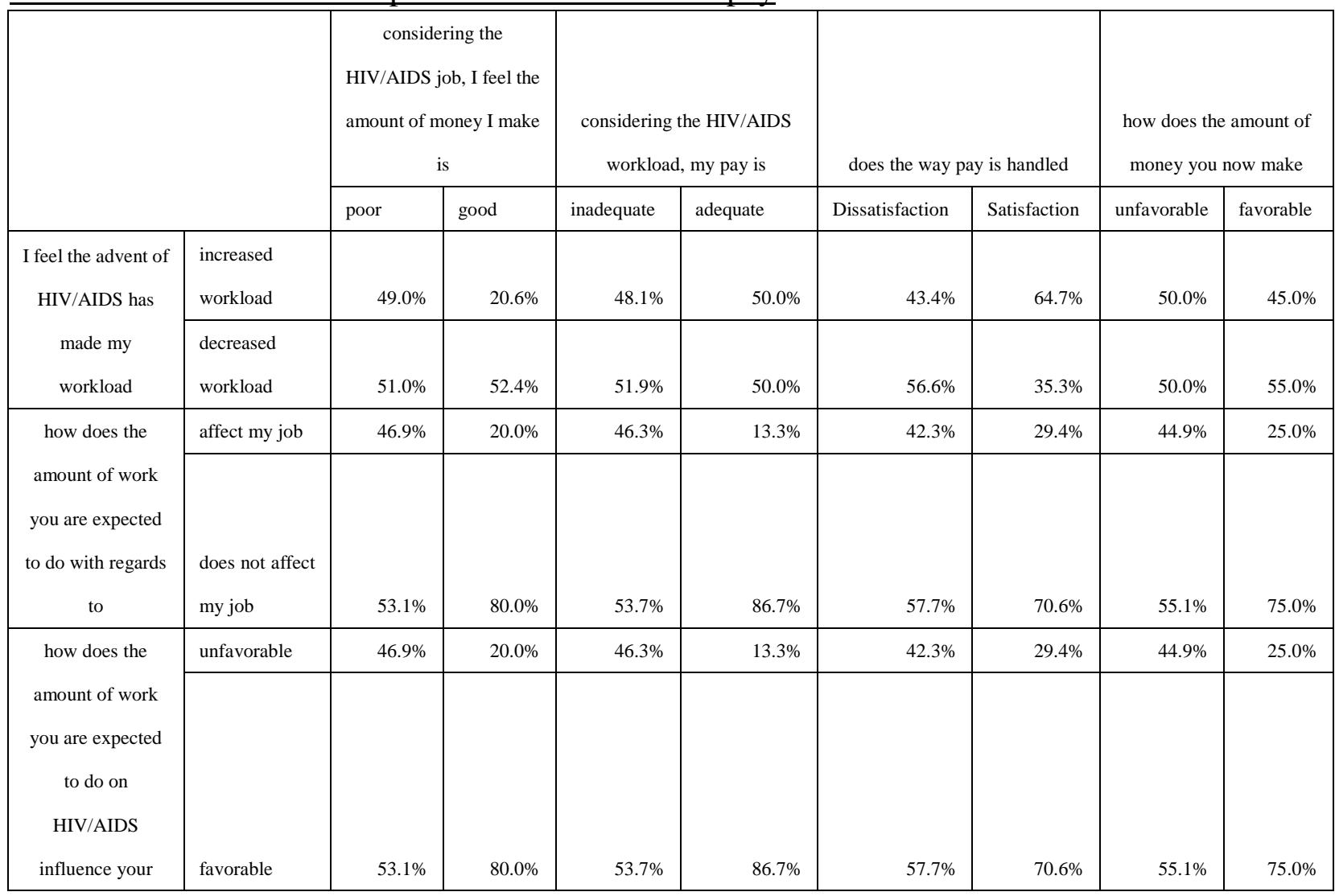




\begin{tabular}{|c|r|r|r|r|r|r|r|r|r|}
\hline overall attitude & & & & & & & & & \\
\hline $\begin{array}{c}\text { how do you feel } \\
\text { about the amount } \\
\text { of work you are } \\
\text { expected to do } \\
\text { with regards to } \\
\text { HIV/AIDS }\end{array}$ & Dissatisfaction & $40.8 \%$ & $20.0 \%$ & $40.7 \%$ & $13.3 \%$ & $36.5 \%$ & $29.4 \%$ & $40.8 \%$ & $20.0 \%$ \\
\hline
\end{tabular}

Table 3 depicts the nurses' perception on workload and their pay in the advent of HIV/AIDS. It shows that majority of nurses $(49.0 \%)$ are not happy with their pay as the workload increases due to HIV/AIDS as opposed to $20.6 \%$ who are content with the amount of money they make. In addition nurses are dissatisfied (40.8\%) with the workload increase due to HIV/AIDS because of unfavorable pay. Generally when the workload increases with little pay, nurse's level of satisfaction goes down.

It is evident from the foregoing study that workload and pay have a positive relationship. Therefore, nurses would anticipate their pay to be increased as the workload increases, of which failure will lead to dissatisfaction. This is because job satisfaction depends on the expectations that individuals have of what their job should provide.

\section{Limitations}

This study had a limitation of a sample size, due to resources and time constraints; therefore it would be beneficial for other researchers to have a large sample size or most appropriately a national sample, so as to enrich the data findings. They should also interview some key stakeholders for instance, government officials, private hospitals and civil society to increase the sample size and scope of the study. This will also help balance the qualitative and quantitative data.

\section{Conclusion}

The importance of nurses in the health care sector cannot be overemphasized. From the findings of the foregoing study we can no longer live under an illusion that nurses' job satisfaction is not affected by HIV/AIDS. The general picture that emerges from the current study is that nurses are dissatisfied with their job, with the major sources of dissatisfaction being the pay and to some extent the workload.

Important to note is that job satisfaction among nurses has been identified as a key factor in nurses' turnover with the empirical literature suggesting that it is related to a number of organizational, professional and personal variables ( $\mathrm{Lu} \&$ Barriball, 2005). Therefore a concern for diminishing job satisfaction of the nurses due to HIV/AIDS should be the pre-occupation of the health care managers in Botswana. However in addressing the dissatisfaction brought by HIV/AIDS in the workplace we should appreciate that economic wise HIV/AIDS issues cannot be divorced from the nursing profession. Rather we should find an amicable way of incorporating this disturbing matter in the nursing profession. In order to arrest the trends, the government of Botswana will be advised to take active steps to 
make the hospitals more pleasant place to work at.

The government should benchmark with Orapa Hospital, on how they have engaged the community in helping the nurses. The hospital allows the patient to be admitted with one of his or her relative who will help take care of them. They help with bathing, feeding and giving emotional support to the patient. This will improve the job life of the nurses by reducing the workload. In addition when the community works closely with the nurses in hospitals, it will help train the community on how to take care of their patients hence a smooth shift to home based care.

The greater complexity of health care services due to HIV/AIDS requires that national policies relating to pay system be considered. This can only be possible if the government appreciate the need to invest more on health workforce. Health is an essential service, hence should be given priority in the national budget. Pay systems should be determined in such a way that all factors involved in the nature of the nursing profession are considered. For example, as much as a mine worker will be compensated for the risk they might incur at the workplace, the same should happen for nurses.

In a nutshell the government of Botswana should pay attention to extrinsic factors (workload and pay) so as to enhance the satisfaction of the nurses. This is important in the era of HIV/AIDS because the whole society depends on the services provided by the nurses in order to maintain, attain optimal health and quality of life. This calls for the government to meet the expectations by the nurses, so that we can have a happy workforce in nursing profession.

\section{Acknowledgement}

This paper comes from the dissertation submitted by Keratilwe Bodilenyane for her Master's degree.

\section{References}

Aiken, L. H. Clark S. P. Cheung, R. B. Sloane, D. M. Silber, J. H. (2003). Educational levels of hospitals nurses and surgical patient mortality. Journal of Management. 290. 1617-23. http://dx.doi.org/10.1001/jama.290.12.1617

Armstrong, M. (2009). Human Resource Management Practice. United Kingdom: Kogan Page Limited.

Blau, G. J., \& Lunz, M. (1998). Testing the incremental effects of professional commitment on intent to leave one's professional beyond the effects of external, personal and work-related variables. Journal of Vocational Behavior. 52. 288-300. http://dx.doi.org/10.1006/jvbe.1997.1601 Coshow, S. M. (2009). The 'Big Dip': Decrements in RN satisfaction at Mid-Career. Nursing Economics. 27 (10). 15-8.

Curtis, E. A. (2008). The effects of biographical variables of on job satisfaction among nurses. British Journal of Nursing. 17 (3). 174-180.

Eugene, W. F. Hamid, M. Karen, A. Stephen, M. (2003). Meaning of Illness and Psychological Adjustment to HIV/AIDS. The Academy of Psychosomatic Medicine. 44. 
485-491.

Economic Commission for Africa. (2004). CHG \& Interactive Botswana. Botswana; Gaborone.

Fako, T. T. (2000). Job satisfaction among the nurses in Botswana. Society in Transition. 31 (1). 10-12.

Fako, T. T. Forcheh, N. Balogi, K. T. O. (2002). Productivity among Nurses and Midwives in Botswana. African Sociological Review. 6 (1). 148-160. http://dx.doi.org/10.4314/asr.v6i1.23207

Fields, D. L. (2002). Taking the measure of work: A guide to validate scales for organizational research and diagnosis. Thousand Oaks: Sage.

Ganetsang, G. (2010). 'Sick and tired- Botswana Public Health Sector. Sunday Standard, 19 July.

Gardulf, A. Soderstrom, I. L. Orton, M. L. Eriksson, L. E. Arnertz, B. Nordstrom, G. (2008). Why do nurses at a university hospital want to quit their jobs. Nursing Management Journal. 13. 329-30.

Herzberg, F. (1966). Work and the Nature of Man. World Publishing Company.

$\mathrm{Hu}$, J. Liu, H. (2004). Job satisfaction among nurses in China. Home Health Care Management \& Practice. 17 (9). 9-13. http://dx.doi.org/10.1177/1084822304268154

IRIN. (2011). Humanitarian news \& analysis. 'Botswana main referral hospital facing crisis'. [Online] Available http://www.irinnews.org/report.aspx?report=51452 [February 8, 2011].

Lu, H. While, A. Barriball, K. (2005). Job satisfaction among nurses: a literature review. International Journal of Nursing Studies 42. (2). 211-227. http://dx.doi.org/10.1016/j.ijnurstu.2004.09.003

Mafuya, N. P. Peltzer, K. (2005). Perceived HIV/AIDS impacts among staff in tertiary institutions in the Eastern Cape, South Africa. Journal of Social Aspects of HIV/AIDS. 2. 277-285. http://dx.doi.org/10.4314\%2Fjpa.v15i1.30629

Pillay, R. (2009). Work satisfaction of professional nurses in South Africa: a comparative analysis of the public and private sectors. Human Resource for Health 2009. 7 (15). 1-10. http://dx.doi.org/10.1186/1478-4491-7-15

Salamon, M. (2000). Industrial Relations in Africa. Houndmills: Palgrave Macmillan

Savery, L. K. (2007). The perceived influence of different items on the job satisfaction of nurses in an Australian hospital is examined. The Journal of Job Satisfaction and Nurses. Emerald Backfiles.

Spector, P. (1996). Job Satisfaction. Thousand Oaks, CA: Sage.

Tawfik, L. (2006). The impact of HIV/AIDS on the health workforce in developing countries. The World Health Report.

Tovey, E. J. Adams A. E. (1999). The changing nature of nurses' job satisfaction: an exploration of sources of satisfaction in the 1990s. Journal of Advanced Nursing. 30 (10). 150-158. http://dx.doi.org/10.1046/j.1365-2648.1999.01059.x

Tshweneyagae, G. T. (2007). Migration of nurses: is there any other option? [Online] Available http://www.mmegi.bw/index.php?sid=18aid=298\&dr=2008/June/Fridayb. [October 10, 2011].

USAID. (2010). Botswana HIV/AIDS Health Profile. [Online] Available http://www.usaid.gov [October 10, 2010]. 


\section{MInstitute Macrothink $_{\text {Int }}$}

International Journal of Human Resource Studies

ISSN 2162-3058

Vroom, V. H. (1964). Some personality determinants of the effects of participation. Englewood Cliffs: Prentice Hall.

World Health Organization. (2006). Health Worker shortages and responses to AIDS. [Online] Available http://www.who.int [September 14, 2010]. 